Original Study

Open Access

Czesław Machelski*

\title{
Contact interactions between soil and a corrugated metal sheet in soil-shell structures under construction
}

https://doi.org/10.2478/sgem-2021-0018

received May 21, 2020; accepted July 8, 2021.

\begin{abstract}
During the construction of soil-shell objects, large deformations of the shell, which is made of corrugated metal sheet, occur. This enables geodetic techniques to be used when monitoring such objects. On this basis, displacements of selected points of the shell are determined, and it is then possible to obtain bending moments, as shown in this paper. Based on measurements using strain gauges in the circumferential band of the shell, internal forces in steel are estimated. The algorithm given in the paper enables the impact of soil on the shell in the examined objects to be analysed. The proposed method of analysing forces in the contact layer becomes especially useful when the static conditions of the model of a shell, which is considered as a bar submerged unilaterally in the soil medium, are met. The paper indicates the possibility of using both measuring techniques. Calculations include a smaller share of axial forces on the contact impact during the laying phase of the backfill. The paper provides examples of the analysis of built shells and record-breaking objects, with an assessment of the effectiveness of the proposed algorithm. Good mapping of contact forces, which were calculated on the basis of bending moments, was indicated even when there was not a dense grid of measuring points. An important advantage of the algorithm involves reduction of the circumferential band that is separated from the soilshell system to the bar, which is an element resulting from the division of the structure into subsystems.
\end{abstract}

Keywords: soil-steel structures; corrugated metal sheets; monitoring of the construction phase; strain gauge and geodetic measurements.

\section{Introduction}

Soil-shell objects that are made of corrugated metal sheet are characterised, among others, by the fact that bearings are not used in them [1, 23]. Therefore, the support conditions of the shell are inherently unstable, which means that the freedom of rotation is not fully preserved (therefore, the occurrence of moments) and, at the same time, displacements are possible. In practice, the design (computational) scheme is sought, i.e. articulated and non-sliding supports in the facility under construction $[1,2]$. The paper considers the construction phase of soil-shell objects when the largest internal forces and displacements are created in the shell [11, 13, 17, 33].

During the construction of soil-shell structure, shell deformations and internal forces are by nature a random phenomenon. Soil impact, which results from its different levels on both sides of the shell and the backfill compaction, is usually not symmetrical. Few-day work breaks are also important $[12,25,26,28]$. Thus, the function of soil interaction on a shell can be diversified [3, $10,34]$. The use of a strain gauge measuring base, which is located on the shell, gives the opportunity to observe changes in the internal forces in the corrugated metal sheet of the object $[6,10]$, deformations $[11,24]$ and the interactions between the backfill and the shell [12, 13]. In order to monitor shells with large spans, strain gauges and geodetic measuring techniques are used simultaneously. In such analyses of soil-shell structures, both measuring techniques are used in order to validate computational algorithms, as is the case in the paper $[4,6-9,18,20,25$, 26, 27-29].

\footnotetext{
*Corresponding author: Czestaw Machelski, Faculty of Civil Engineering, Wroclaw University of Science and Technology, E-mail: czeslaw.machelski@pwr.edu.pl
} 


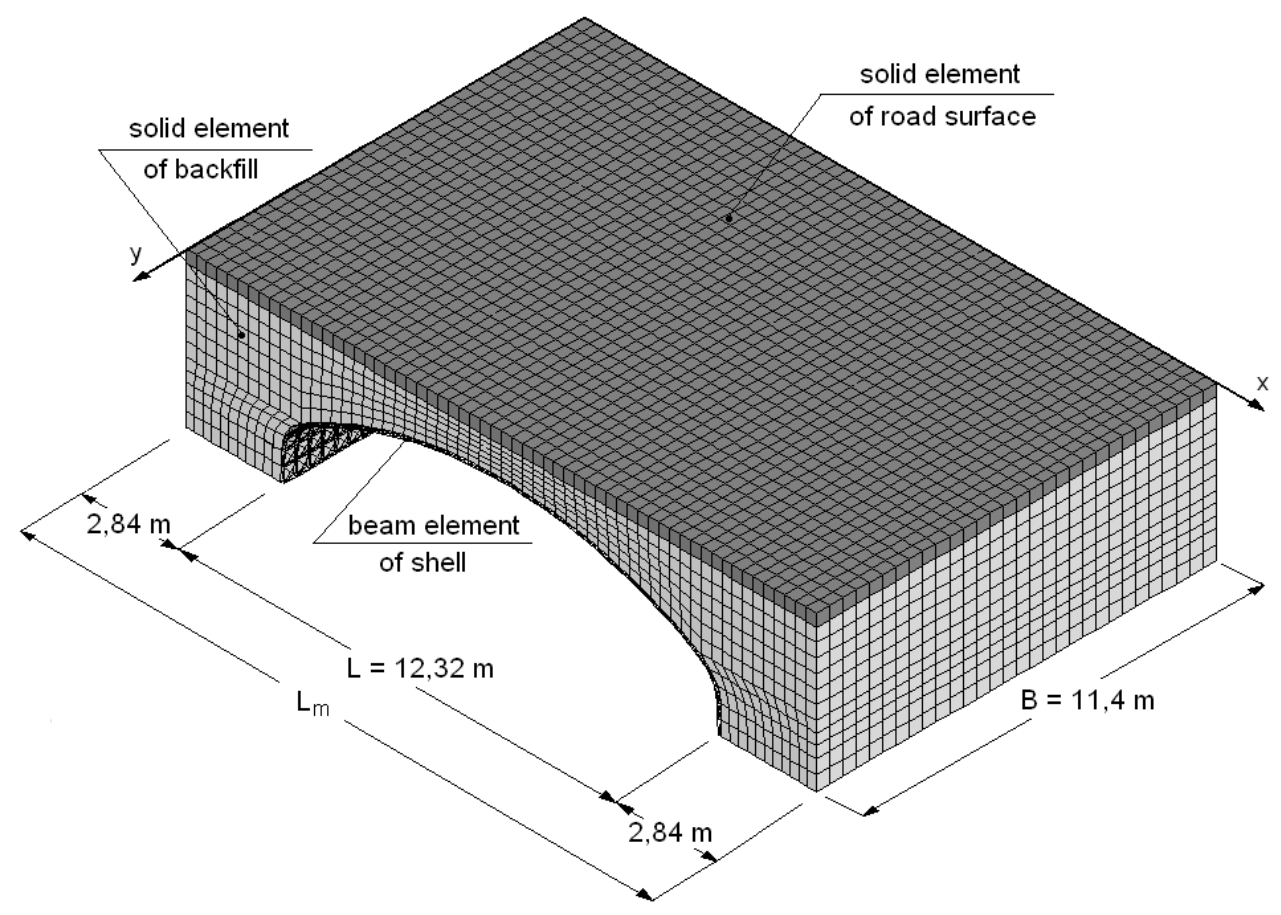

Figure 1: 3D model of a soil-shell object [14, 15].

\section{Hybrid model of a soil-shell object}

A characteristic feature of soil-shell objects as a subgroup of integrated structures [15], unlike in classic bridges, is the adoption of soil backfill as the basic material of the object and also the high impact of the road surface as loadbearing elements $[15,16]$. A special principle concerning the hybrid bridge model [15] is division of the structure into subsystems [11-14, 16]. In the computational model of the object given in Figure 1, the shell is distinguished as the basic subsystem and backfill with layers of the road surface of the bridge structure as the second subsystem. The interaction of both subsystems takes place in the contact layer - it is included in the form of a static condition of reciprocity of soil interaction on the shell. At the same time, displacement compliance is not taken into account, i.e. slipping in the contact layer between these subsystems is permissible. This is an important advantage of the algorithm, which reflects the work principle of such constructions.

The paper presents the results of measurements on a real object, i.e. obtained in a 3D system, and also those obtained from the static scheme of the 2D circumferential band, as in Figure 2, i.e. from the computational model. The possibility of reducing the model from 3D to 2D space results from the assumption of longitudinal symmetry of the structure and also analysis of soil interactions on the shell. The author uses the possibility of changing the 3D system into the perimeter section of an object. Therefore, the main advantage of the solution proposed in the paper is the analysis of a selected (examined) fragment of the structure of an object in the form of a bar with the shape of a parabola under the influence of soil, as in Figure 2. In the 2D model, the static scheme of the circumferential band of the shell is taken into account. The results of strain gauge measurements encode the shell deformations, which are obtained from geodetic measurements (as in Fig. 2a), and also the associated internal forces calculated on the basis of results of the strain gauge measurements (as in Fig. $2 b$ ). In the paper, the effects of displacements and internal forces are treated as the result of soil interaction on the shell during the construction phase of an object.

\section{Internal forces in the circumferential band of the shell}

The basic example used in the paper is an object in Ostróda [12], which is the largest such structure in Poland. The geometrical characteristics of the shell, as can be seen in Figure 4, involve its shape in the form of circle sections 
a)

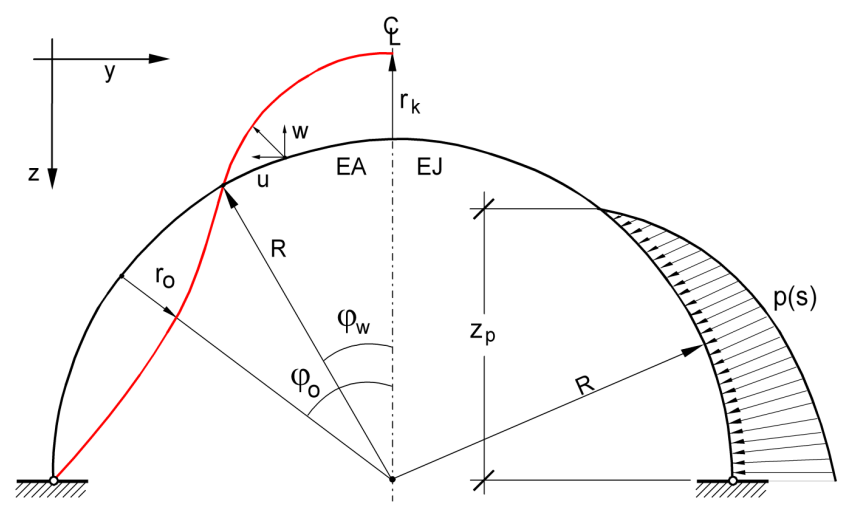

b)

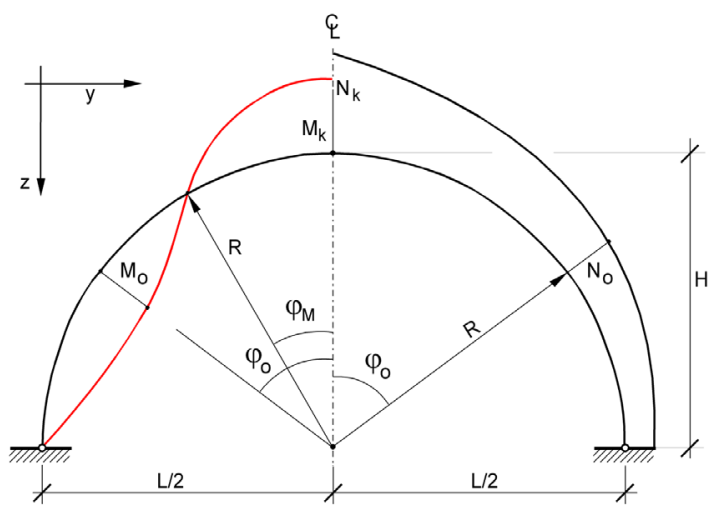

Figure 2: Scheme of the soil interaction with internal forces due to the deformation of the circumferential band of the shell.

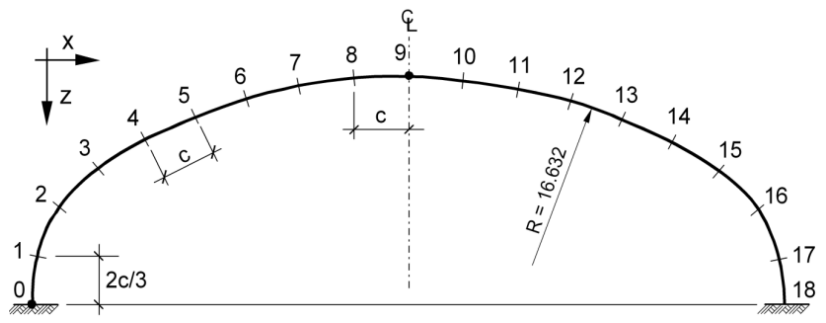

Figure 3: Division into elements in the circumferential band.

with a curvature radius $R=16.632 \mathrm{~m}$ and the radius in the corner $R_{n}=6.12 \mathrm{~m}$, span $L=25.724 \mathrm{~m}$ and the height of the shell $H=9.11 \mathrm{~m}$. The geometry of the corrugated metal sheet is included in its technical designation UC $500 \times 237 \times 9.65$. It is an UltraCor type with the following parameters: $a=500 \mathrm{~mm}$ - wavelength, $f=237 \mathrm{~mm}$ - its height and $g=9.65 \mathrm{~mm}$ - its thickness. While monitoring the object during the construction phase, strain gauge measurements were made in the points given in Figure 3 and geodetic measurements in the points that were distant from each other by $2 c$.

The author determined the internal forces in the shell using a strain gauge measuring base. On the selected circumferential band of the shell, strain gauges were glued onto the corrugated sheet surface that was accessible from the inside, as can be seen in Figure $4 \mathrm{~b}$. In each measuring section, the sensors were arranged in pairs at the apex and on the corrugation valley - and located in the direction of the circumferential band of the shell, as can be seen in Figure 4b. The twin sensor system and adoption of the principle of plain cross-sections enable deformations in the inertia axis of the cross-section of the corrugated metal sheet to be determined, and therefore, also the circumferential axial forces from the following relationship to be designated:

$$
N=E A \cdot \varepsilon=E A \frac{\varepsilon_{D}(f-g)+\varepsilon_{g}(f+g)}{2 f} .
$$

Equation (1) contains the geometry of the corrugated metal sheet, as can be seen in Figure 4b. In order to determine the change in curvature $\kappa$ and the radius of curvature of the shell $\rho$, the geometrical relationships of the sheet and also $\varepsilon_{D}$ and $\varepsilon_{g}$ can be used. The bending moment can be then determined as follows:

$$
M=E I \cdot \kappa=E I \frac{\varepsilon_{g}-\varepsilon_{D}}{f} .
$$

Figures 5 and 6 show diagrams of the internal forces in the shell, which were obtained from equations (1) and (2), when stiffness $E A=1487 \mathrm{MN}$, and $E I=9.918 \mathrm{MN} \mathrm{m}^{2}$ for the width of a band $a=0.5 \mathrm{~m}$. Three characteristic phases of the construction, i.e. laying of the backfill, when $z_{\mathrm{g}}$ determines the thickness of the backfill, were selected as in Figure 2a. During the construction phase, the backfill is laid with mechanical compaction in layers that are 30-cm thick. During technical breaks, measurements of the shell deformations were carried out using selected monitoring techniques. When $z_{\mathrm{g}}=H=9.2 \mathrm{~m}$, the level of the backfill reaches the key and the overburden layer of soil is then formed above the shell. Small changes in bending moments as a function of backfill thickness result from the diagrams given in Figure 5. Axial forces are subjected to significant changes, in particular, in the area of change in the radius of curvature in the corners, i.e. in points $1,2,3,15,16$, and 17 . The diagrams are presented in an expanded form on the circumferential band of the shell, i.e. in a rectangular system, and not as in Figure 2, with regards to the curvilinear axis of the bar. 
a)

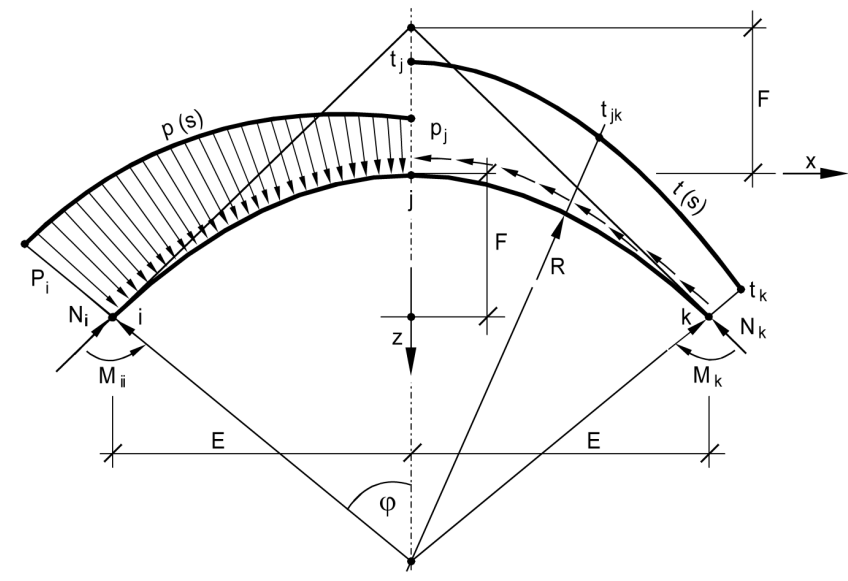

b)

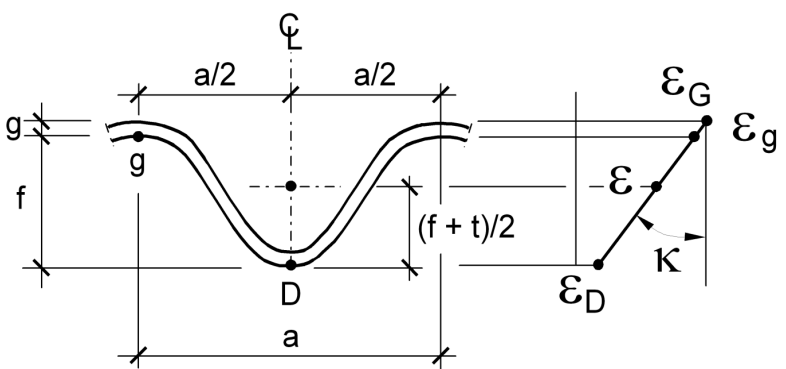

Figure 4: Distribution of contact forces between the subsystems and also the R3 measuring base of the shell.

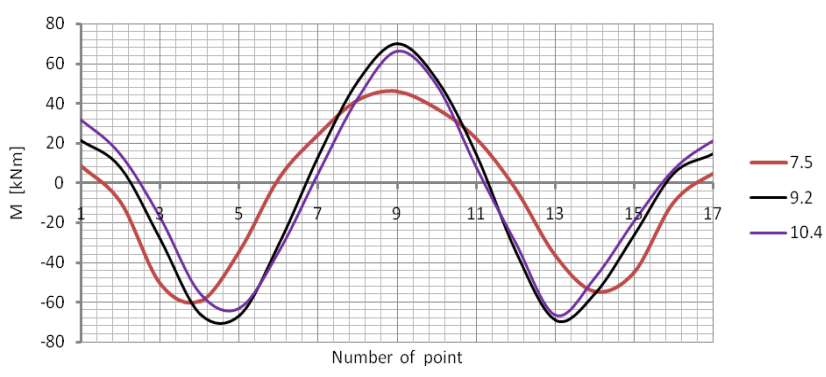

Figure 5: Diagrams of bending moments with regards to the backfill thickness $\mathrm{z}_{\mathrm{g}}$.

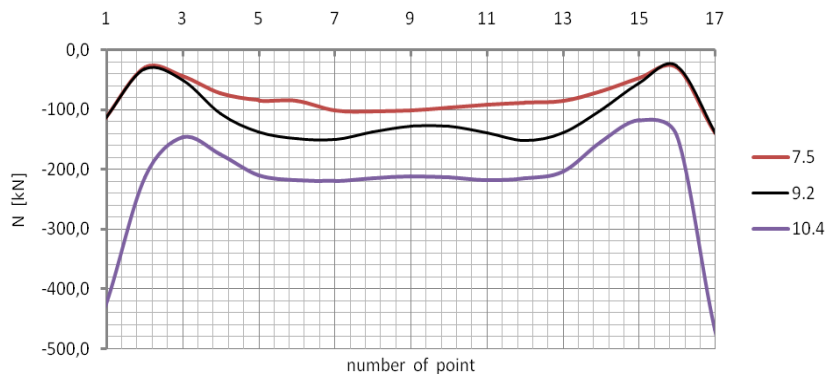

Figure 6: Diagrams of axial forces with regards to the backfill thickness $z_{\mathrm{g}}$.

In the case of a support zone, extreme values of axial forces appear when the ground is placed above the shell $\left(z_{\mathrm{g}}>H\right)$. In addition, in this area, a radius of curvature reduced to the value of $R_{\mathrm{n}}=6.32 \mathrm{~m}$ occurs. With an increase in backfill thickness, the moment of shell fixation in the support increases significantly, as in Figure 5. Moreover, the radial direction of the pressure force $p$ changes in the support area. Therefore, the shell's support area should be considered separately as a local issue.

\section{Impact of soil on the shell}

Figure $4 \mathrm{a}$ shows the distribution of $p(\mathrm{~s})$ and $t(\mathrm{~s})$ interactions along the length of the analysed segment of the shell's circumferential band. The pressure, $p(\mathrm{~s})$, which is given in the measuring points (as in Fig. 4a), is directed radially, i.e. in accordance with radius $R$. From the functions of internal forces $N(\mathrm{~s})$ and $M(\mathrm{~s})$, normal interactions distributed along the circumferential band of the shell $s$

\[ p(s)=\frac{d^{2} M}{d s^{2}}+\frac{N}{R} \]
and tangential interactions

$$
t(s)=\frac{d N}{d s}+\frac{d M}{d s} \frac{1}{R} .
$$

are obtained. In the case of a dense grid of measuring points, as in Figure 3, equation (3) can be used in order to determine the forces of normal interaction $p(\mathrm{~s})$, which in a differential approach [12, 21, 22] will take the following form:

$$
p_{j}=\frac{1}{c^{2}}\left(M_{j-1}-2 \cdot M_{j}+M_{j+1}\right)+\frac{N_{j}}{R} .
$$

When two adjacent sections are considered, as is the case presented in Figure 4a, the global radius of curvature, which is given in Figures 1-3, results from the geometrical dependencies as in the relationship

$$
R=\frac{F^{2}+E^{2}}{2 F} .
$$


Therefore, the length of the examined section, as a sector of a circle, is equal to

$$
z=R \cdot \varphi
$$

With a significant radius $R=16.632 \mathrm{~m}$, and a dense grid of division into elements, as in Figure 3, the angle between the measuring points is equal to

$$
\varphi=\frac{\pi}{26}
$$

When the chord length is $c=2.0 \mathrm{~m}$, the arc length $z=2.01$ $\mathrm{m}$ is obtained from equation (8). Therefore, the value of $c$, considered as the arc length, is used in the paper.

The share of components derived from both internal forces $M$ and $N$ in the shell are compared in Figure 7, as in the equation

$$
p=p(M)+p(N) .
$$

Two selected construction phases were adopted as characteristic ones. A distinguished special situation is the one in which the backfill reaches the shell's crown, i.e. $z_{\mathrm{g}}=H$, and also the beginning of formation of soil above the shell when $z_{\mathrm{g}}=10.4 \mathrm{~m}$. On comparison of these diagrams, it is observed that the components derived from bending and compression are equivalent when $z_{\mathrm{g}}<$ $H$. Axial forces are important when there is an increase in thickness of the backfill. When $z_{\mathrm{g}}>H$, there is a significant increase in these forces, especially around the support and the corner. This can be seen in Figure 6 . In the case of significant backfill thicknesses, the second component from equation (5) becomes dominant, which in literature [32] appears as the relationship $p=N / R$.

In the section of the shell where it is free of soil influence, i.e. when $z_{\mathrm{g}}<H$, the relation $p(\mathrm{M})=p(\mathrm{~N})$ should be applied. This principle is approximately met in Figure 7 (in point 9 when $z_{\mathrm{g}}=H$ ). The above conclusions are consistent with the observations of White and Layer, Marston and Spangler, and also Vaslestad [32] from their studies on susceptible shells immersed in the ground. Soil interactions on the shell differ significantly from the soil pressure on rigid walls according to Coulomb. Changes in impacts, considered as a long-term process, are an important factor in exploited facilities. They were, therefore, the subject of research conducted with the use of pressure gauges [32]. The determination of functions $p(\mathrm{~s})$ and $t(\mathrm{~s})$, as in Figure 4a, enables a separate analysis of the shell, as a subsystem derived from the structure in the form of its circumferential band, to be conducted.

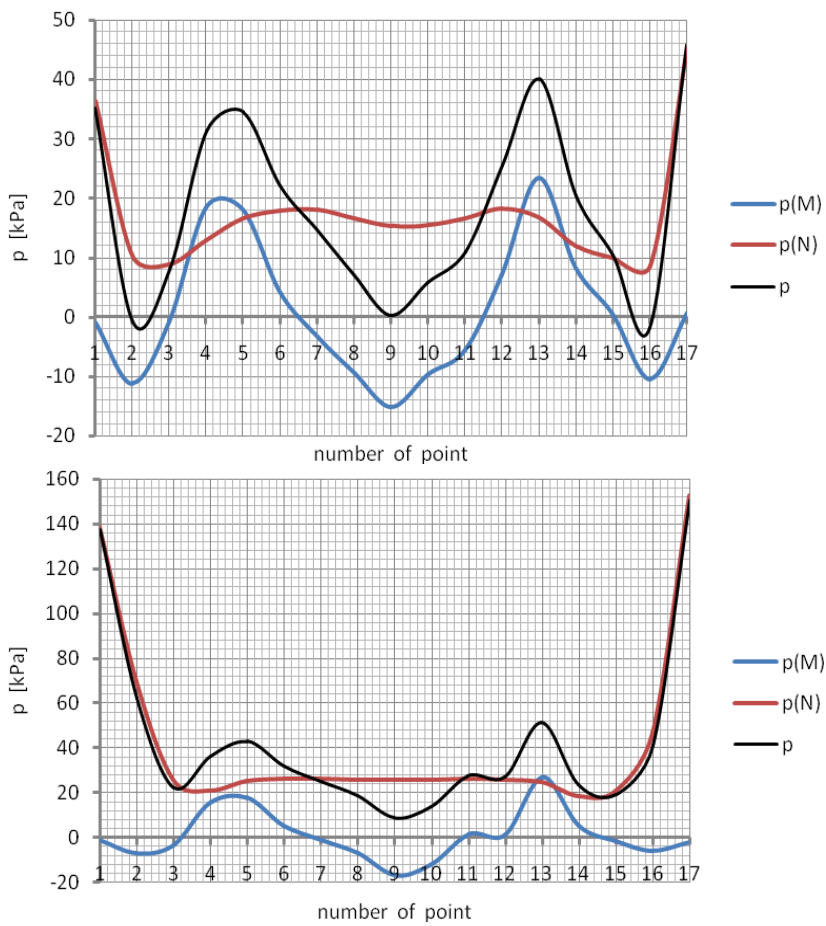

Figure 7: Comparison of the impact of bending and axial forces on soil pressure.

\section{The dependence between bending moments and soil pressure}

In order to discretise the structure in this computational model, bar elements were used, as in Figures 1-4. They enable the function of the influence of internal forces, which are convenient for the calculations in the case of loads that change their position, to be created. The effectiveness of this model was verified in [14]. The computational algorithm uses the functions of the influence of bending moments $f(s)$ with the forms as in Figure 8 when the model of the circumferential band of the shell is an arch bar as in Figure 3.

In the plain model of the $2 \mathrm{D}$ circumferential band of the 2D shell, the interaction of $p(\mathrm{~s})$ with the bending moment in the $k$ point of the $M_{\mathrm{k}}$ shell is related to the influence function $f_{\mathrm{k}}$, as in the equation:

$$
M_{k}=\int_{0}^{L s} p(s) \cdot f_{k}(s) d s .
$$

With the same distributed force $p(\mathrm{~s})$, different $M$ values are obtained in each point of the shell. This is because the shapes of the influence function $f(\mathrm{~s})$ are different. Both functions are implicated in equation (10). Because the purpose of the paper is to determine the pressure function 


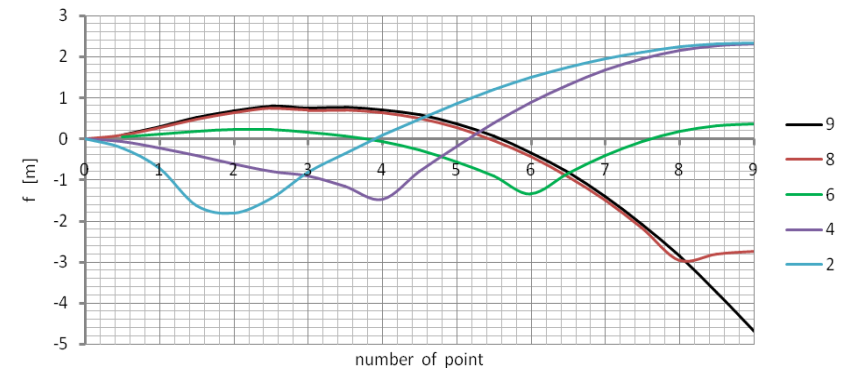

Figure 8: Functions of the influence of bending moments for the analysed shell's points.

$p(\mathrm{~s})$ solely on the basis of bending moments $M(\mathrm{~s})$, equation (10) is not useful for this solution. Usually, internal forces are calculated based on the given load, whereas in the paper there is a reverse task.

The paper proposes the solution of a continuous system, as in equation (10), as a transformation into a discrete system, in which the arch is divided into sections with uniformly distributed loads (as in Fig. 9a). Therefore, equation (10) is transformed into a system of equations with the form

$$
\boldsymbol{F} \cdot \boldsymbol{p}=\boldsymbol{m}
$$

and in detail, it will have the form

$$
\left[\begin{array}{cccccc}
F_{1}^{1} & F_{1}^{2} & \bullet & F_{1}^{j} & \bullet & F_{1}^{n} \\
F_{2}^{1} & F_{2}^{2} & \bullet & F_{2}^{j} & \bullet & F_{2}^{n} \\
\bullet & \bullet & \bullet & \bullet & \bullet & \bullet \\
F_{k}^{1} & F_{k}^{2} & \bullet & F_{k}^{j} & \bullet & F_{k}^{n} \\
\bullet & \bullet & \bullet & \bullet & \bullet & \bullet \\
\bullet & \bullet & \bullet & F_{n}^{j} & \bullet & F_{n}^{n}
\end{array}\right] \cdot\left[\begin{array}{c}
p_{1} \\
p_{2} \\
\bullet \\
p_{j} \\
\bullet \\
p_{n}
\end{array}\right]=\left[\begin{array}{c}
M_{1} \\
M_{2} \\
\bullet \\
M_{k} \\
\bullet \\
M_{n}
\end{array}\right] \cdot
$$

Pressure forces, which are distributed along the sections of the circumferential band of the shell, are summarised in vector

$$
\boldsymbol{p}=\operatorname{col}\left\{\mathrm{p}_{1} p_{2} \quad p_{j} \quad p_{n}\right\}
$$

and the bending moments in the measuring points, which are associated with them, take the form as in the equation

$$
\boldsymbol{m}=\operatorname{col}\left\{\mathrm{M}_{1} M_{2} \quad M_{k} \quad M_{\mathrm{n}}\right\}
$$

Thus, the terms of vector $\boldsymbol{m}$ are the values of the moments in the points that are shown in Figure 5.

In the system of equations (12), the elements of matrix $\boldsymbol{F}$ are the areas of the section of the influence function $f(\mathrm{x})$

a)

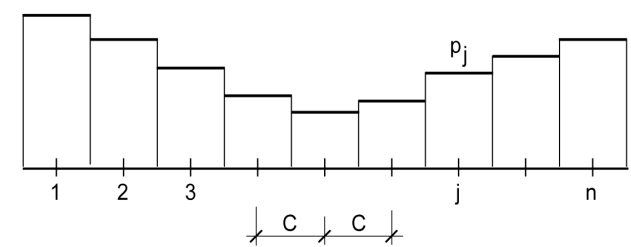

b)

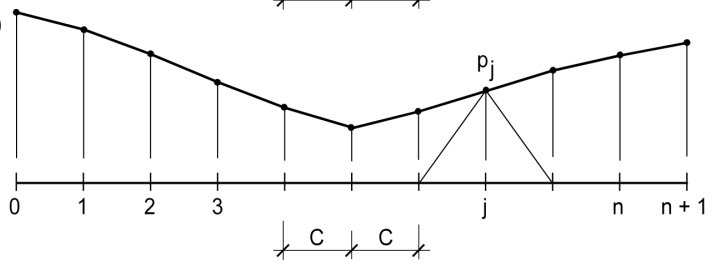

c)

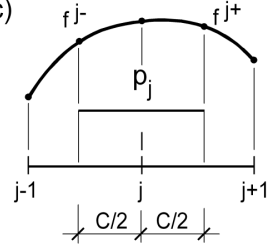

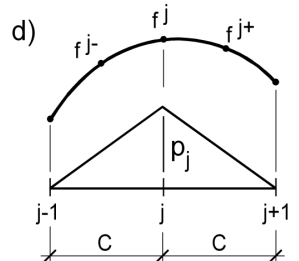

e)

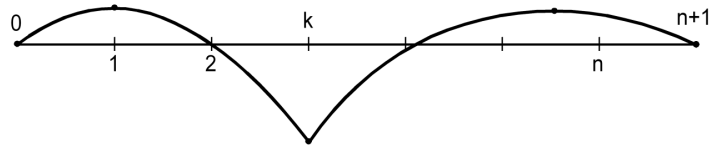

Figure 9: Calculation diagrams of the normal interaction function.

calculated as in the case of $F_{k}^{j}$ from the Simpson formula in the form of

$$
F_{k}^{j}=\frac{c}{6}\left(f_{k}^{j-}+4 f_{k}^{j}+f_{k}^{j+}\right) .
$$

The graphic interpretation of equation (15) is shown in Figure $9 \mathrm{c}$, where the points $j-$ and $j+$ are the middle points on sections with length $c$.

In Figure 9b, an example of using the function in the form of a polyline is considered. In the scheme shown in Figure 9d, two adjacent sections with a common point $j$ are considered. When assuming the designations of functions $f_{\mathrm{k}}(\mathrm{s})$ and $p(\mathrm{~s})$, as in this diagram, the following two equations based on equation (15) are obtained:

$$
M_{k}^{j-}=\frac{c}{6}\left[f_{k}^{j-1} \cdot p_{j-1}+f_{k}^{j} \cdot p_{j}+2 f_{k}^{j-}\left(p_{j-1}+p_{j}\right)\right]
$$

and

$$
M_{k}^{j+}=\frac{c}{6}\left[f_{k}^{j} \cdot p_{j}+f_{k}^{j+1} \cdot p_{j+1}+2 f_{k}^{j+}\left(p_{j}+p_{j+1}\right)\right] .
$$


While adopting the analysed quantity $p_{\mathrm{j}}$ from these two equations, the following equation can be formed:

$$
M_{k}^{j}=\frac{p_{j} \cdot c}{3}\left[f_{k}^{j-}+f_{k}^{j}+f_{k}^{j+}\right] .
$$

Therefore, the terms of matrix $F$ are in the form

$$
F_{k}^{j}=\frac{c}{3}\left[f_{k}^{j-}+f_{k}^{j}+f_{k}^{j+}\right]
$$

A very important solution in this approach is the separation from loads that occur in equations (15) and (19). This enables a system of equations as in (12), with a vector of load $\boldsymbol{p}$, and also vectors of constant terms $\boldsymbol{m}$ to be formulated. However, the interpretation of term $p_{\text {i }}$, which is given in Figure 9a and b, is completely different these are the values in the points of division into sections, and not constant values in the entire section with the central point as in Figure 9c and d. The terms of matrix $\boldsymbol{F}$ calculated previously from equation (15) or (19) are also subject to change.

From the formulation of the system of equations (12), it is possible to solve this system (when matrix $\boldsymbol{F}$ is not singular), i.e. it is possible to determine the elements of vector $\boldsymbol{p}$. Therefore, when in the study, and in the shell's geometry (as in Fig. 3), there are $n=17$ points in which strain gauge measurements were carried out, it is possible to obtain 17 values of loads, as in Figure 9a or b. In the algorithm that was presented earlier, soil interactions with bending moments occurring in the object, i.e. the 3D system, were connected through dependencies that occurred in the 2D model of the object in the form of an influence function. It is assumed in the calculations that the real soil impact on the shell $p(\mathrm{~s})$ is approximated in the form of $p_{\mathrm{j}}$ values that are included in vector $\boldsymbol{p}$ (13). Due to simplifications, dispersed $p_{\mathrm{i}}$ values are obtained from the system of equations (12). They do not correspond to the forms of function $p(\mathrm{~s})$, which are shown in Figure 7. Therefore, the algorithm in the form of the system of equations (12), which was presented earlier, is ineffective.

$$
\boldsymbol{m}_{\mathrm{it}}=\boldsymbol{F} \cdot \boldsymbol{p}
$$

come from the iterative process. Iteration is started with $p_{\mathrm{j}}$ values that were obtained from the Coulomb model (for the shell considered as a rigid wall), and the process is considered complete when the terms of vector

$$
\mathbf{m}_{i t}=\operatorname{col}\left\{M_{1}^{i t} M_{2}^{i t} \ldots \ldots . . . M_{k}^{i t} \quad \ldots \ldots . . . M_{n}^{i t}\right\}
$$

differ enough from the elements $\boldsymbol{m}$ that are obtained from measurements and equation (2). Based on the differences in bending moments, the estimation index is calculated as

$$
r_{k}=\frac{M_{k}^{t}-M_{k}}{M_{k}} 100 \% \text {. }
$$

It plays the role of a criterion for assessing the convergence of the iterative process.

The advantage of the iterative solution algorithm is that vectors $\boldsymbol{p}$ and $\boldsymbol{m}$ can be of any size, and therefore, matrix $\boldsymbol{F}$ does not have to be square. Thus, in this approach, matrix $\boldsymbol{F}$ is transformed into a system with any number of rows and columns. If the assumption about the symmetry of interactions and circumferential band deformations is used, the task can be further reduced by half. Another simplification is adoption of a limited number of measuring points and bending moments, as in the example that is considered in the paper:

$$
\boldsymbol{m}=\operatorname{col}\left\{\mathrm{M}_{2} \quad M_{4} \quad M_{6} \quad M_{8} \quad M_{9}\right\}
$$

Due to this, it is possible to maintain the original number of points at which the $p_{j}$ forces are determined, as in Figure 4 , and listed in vector

$$
\boldsymbol{p}=\operatorname{col}\left\{p_{1} p_{2} \quad p_{j} \quad p_{9}\right\} .
$$

The narrowed calculation system (equations) can now be presented in the form

$$
\left[\begin{array}{cccccc}
F_{2}^{1} & F_{2}^{2} & \bullet & F_{2}^{j} & \bullet & F_{2}^{9} \\
F_{4}^{1} & F_{4}^{2} & \bullet & F_{4}^{j} & \bullet & F_{4}^{9} \\
\bullet & \bullet & \bullet & \bullet & \bullet & \bullet \\
F_{8}^{1} & F_{8}^{2} & \bullet & F_{8}^{j} & \bullet & F_{8}^{9} \\
F_{9}^{1} & F_{9}^{2} & \bullet & F_{9}^{j} & \bullet & F_{9}^{9}
\end{array}\right] \cdot\left[\begin{array}{c}
p_{1} \\
p_{2} \\
\bullet \\
p_{j} \\
\bullet \\
p_{9}
\end{array}\right]=\left[\begin{array}{c}
M_{2} \\
M_{4} \\
M_{6} \\
M_{8} \\
M_{9}
\end{array}\right] .
$$

The system of equations (12) can be used in an inverse algorithm when the interactions $p_{\mathrm{j}}$ from equation (13) and the bending moments

\section{Iterative algorithm of the solution}



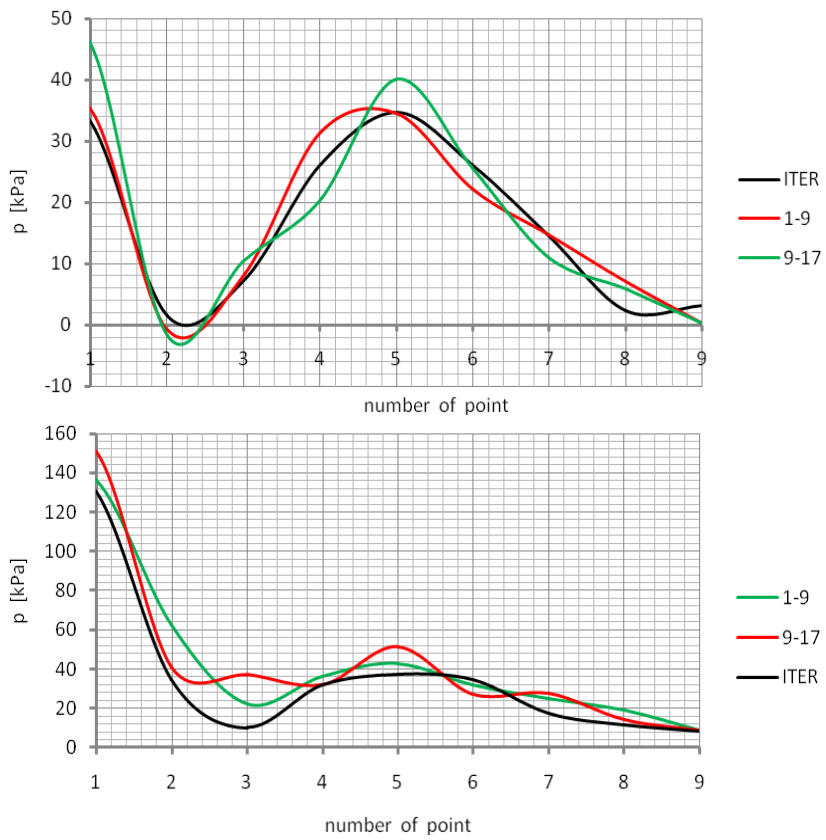

Figure 10: Intensity of normal interaction in the contact layer.

As a result of iteration, a polyline is obtained as in Figure 9b, with terms $p_{\mathrm{i}}$, which form vector $\boldsymbol{p}$ (24). However, it should be remembered that the actual load function is complex and the result of calculations is only approximation of this function. It is important that the calculations are carried out using the 2D model of the circumferential band of the shell, and the aim is to obtain bending moments in the measuring points of the real structure, and thus in the $3 \mathrm{D}$ system.

The effectiveness of theiterativealgorithmisillustrated using the previously analysed example of the object in Ostróda [6], which has the numbering of measurement points as in Figure 3. Figure 5 compares diagrams of the bending moments that form vector $\boldsymbol{m}$, which are treated as accurate. Figure 10 compares the calculation results that were obtained from implementation of the iterative algorithm and from equation (5). Two characteristic construction phases were considered, i.e. laying the backfill when $z_{\mathrm{g}}$ determines its thickness as in Figure 2a and also when $z_{\mathrm{g}}=H=9.2 \mathrm{~m}$, and the level of the backfill reaches the crown and the overburden layer is formed above the shell $-z_{\mathrm{g}}=10.4 \mathrm{~m}$.

The diagrams show support moments and the very significant influence of the shell's corner geometry in the form of a reduced radius of curvature $\left(R_{\mathrm{n}}=6.12 \mathrm{~m}\right)$. In the case when the layer above the shell was $1.3-\mathrm{m}$ thick, i.e. with a backfill thickness $z_{\mathrm{g}}=10.4 \mathrm{~m}$, the soil pressure on the key $p_{9} \approx 9 \mathrm{kPa}$ was obtained. This is a visible effect of the formation of a vault inside the soil because this value does not result from the weight of the soil above the shell, as the volumetric weight is equal to $20.4 \mathrm{kN} / \mathrm{m}^{3}$. In literature, such a situation is known as the vaulting effect.

When the pressure $p_{\mathrm{j}}$ is considered as in Figure 10, bending moments are obtained from equation (20) and are summarised in vector $\boldsymbol{m}_{\mathrm{it}}$ in equation (21). On this basis, the diagrams presented in Figure 11 were made. These diagrams were related to the results shown in Figure 5. The bending moments that were obtained from strain gauge measurements form two branches with a common point in the key. Good convergence of these diagrams indicates the effectiveness of the estimation that was obtained from the iterative algorithm. It is important that the diagrams were obtained by adopting large simplifications and then calculated with completely different assumptions: equation (5) and algorithm in equation (20). The compared diagrams were obtained from a simplified 2D model and from a 3D object that is being built. The computational example assumes symmetry of the shell's deformations.

The paper intentionally omitted the analysis of tangential forces $t(\mathrm{~s})$, as in Figure 4a. They are determined on the section between points $j$ and $k$ from equation (4), but in the differential approach as

$$
t_{j k}=\frac{1}{c}\left[N_{k}-N_{j}+\frac{1}{R}\left(M_{k}-M_{j}\right)\right] .
$$

These forces change the sign (direction of action) in the area of the crown, and in addition, are usually small during the construction phase. In the support area, and in the change in geometry in the corner of the shell, the course of these forces is complex, and they are therefore omitted in Figure 12.

When striving to obtain a greater accuracy of contact interactions, the geometry of the corrugated metal sheet must be taken into account, as in Figure 1b. Therefore, the calculated values of $p$ and $t$, considered for a circumferential band with the shape of a circle segment, are certainly different than in a real system: between the apex and the wave valley, and on the sidewalls. The corrugated metal sheet also has lateral interactions, which are omitted in the 2D model. From the strain gauge measurements of unit strains, comparable values of $\varepsilon_{x}$, in circumferential direction, and $\varepsilon_{\mathrm{y}}$, as the bending effect in the perpendicular direction, are sometimes obtained. Therefore, if the shell's geometry was a surface with a constant thickness, interpretation of the analysis results would be easier. 

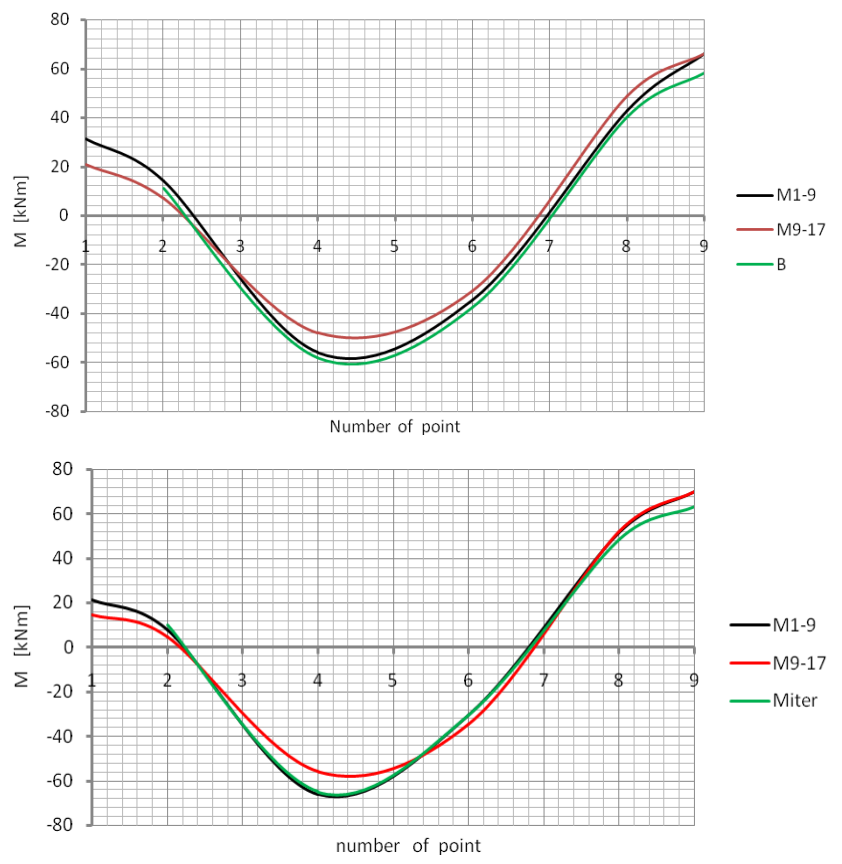

Figure 11: Comparison of bending moments for the purpose of evaluating effectiveness of the algorithm.

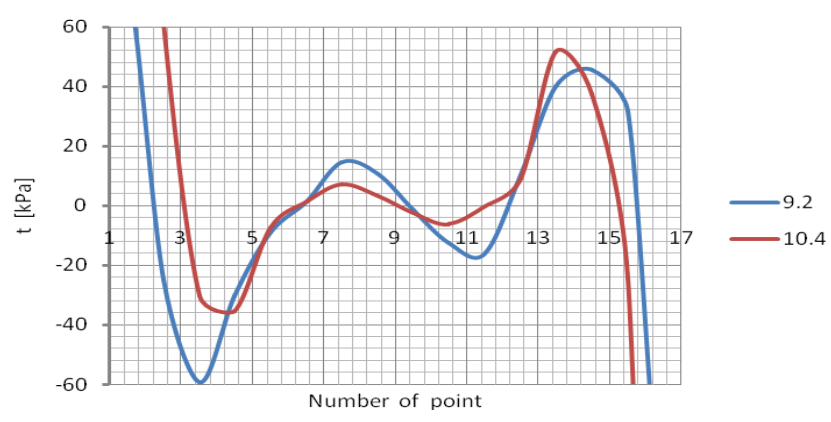

Figure 12: Intensity of the tangential interaction in the contact layer.

\section{The use of geodetic measurements for the purpose of assessing soil pressure}

In the case of using the results of strain gauges, equations (1)-(5), or the iterative algorithm with the results given earlier in the paper, are used to determine the contact interactions. During the construction phase of embankments, and thus also during the laying of the backfill next to the shell, geodetic measurements are carried out as a technological requirement. From such measurements, coordinates of the observed points on the shell are obtained, as in Figure 3. After relating them to the initial phase, information on changes in the shell's deformation is obtained. Therefore, during the construction, results are obtained in the form of vertical and horizontal components of displacements. From them, displacements are obtained in a radial direction $r$ (consistent with the radius of curvature of the circumferential band $R$ ), as can be seen in Figure 2 .

The measurement results from the construction of the Shumal Bridge facility in Ras Al Khajmah near Dubai are presented below [30]. This facility currently has a record span. The geometrical characteristics of its shell, as can be seen in Figure 4, involve its shape in the form of circular sections with a radius of curvature $R=29.68 \mathrm{~m}$ and in the corner $R_{\mathrm{n}}=8.39 \mathrm{~m}$. This shell has a span $L=32.39 \mathrm{~m}$ and a height $H=9.57 \mathrm{~m}$. The geometry of the corrugated metal sheet is included in its technical designation UC 500 $\times 237 \times 12$. During construction, and during monitoring of the object, strain gauge and geodetic measurements were carried out in the same points as in the Ostróda object (given in Fig. 3). Figure 13 presents the diagrams of displacements in the direction of the radius of curvature in the circumferential band, which were obtained from geodetic measurements [30]. On the horizontal axis, the markings of measuring points were adopted from Figure 4.

Two characteristic phases of construction were considered in the paper: when the level of the backfill is close to the key with $z_{\mathrm{g}}=H$ and when there is a layer of soil above the shell [30]. In this case, asymmetrical levels of backfill were used on the construction site on both sides of the shell, which are visible in the key of the diagrams in Figure 13 (values of $z_{\mathrm{g}}$ ). This technical procedure is usually carried out in the case of an inclined overburden layer [31]. This causes a disturbance of the shell's deformation symmetry, and in particular, in the lateral part of the shell, which is visible on the $r$ (s) diagrams.

Radial displacements that are obtained from geodetic measurements can be used to calculate bending moments from differential relationship [6]

$$
M_{j}=E \cdot \kappa(r)=\frac{E}{c^{2}}\left[r_{i}-\left(2-\frac{c^{2}}{R^{2}}\right) r_{j}+r_{k}\right] .
$$

In this equation, there are constant parameters of the analysed object

$$
\frac{E I}{c^{2}}=\frac{11.4}{2.5^{2}} \cdot 10^{3}=1824 k N
$$

There is a small effect of curvature change in the shell's key area 


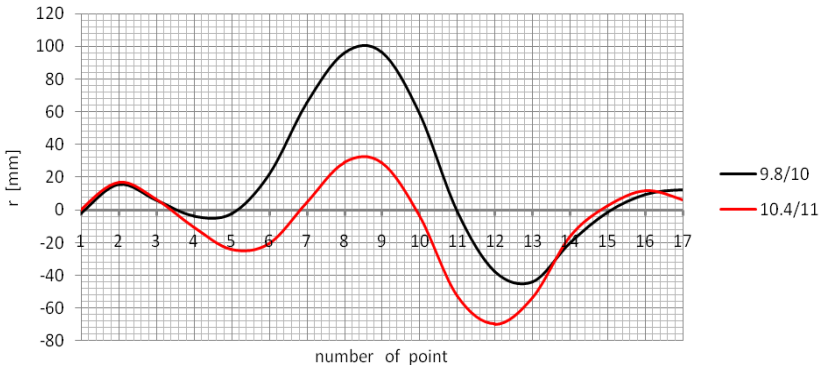

Figure 13: Radial displacements of the shell.

$$
2-\left(\frac{c}{R}\right)^{2}=2-\frac{2,5^{2}}{29.68^{2}}=1,993
$$

and a slightly larger effect in the corner of the shell

$$
2-\left(\frac{c}{R_{n}}\right)^{2}=2-\frac{2,5^{2}}{8.39^{2}}=1,911
$$

Figure 14 compares the bending moment diagrams, which were calculated from equation (27) based on displacements and relationships in equation (2), with the bending moments obtained based on strain gauge measurements. Their similarity can especially be seen in the shape and ordinate values of these diagrams. Therefore, the results of geodetic measurements and the bending moments calculated on their basis can be used to estimate the soil pressure according to the iterative algorithm presented earlier.

In the case of this object, a significant number of points (as in Fig. 3), with limited accuracy of geodetic measurements $(1 \mathrm{~mm})$, cause additional waves of the $M(\mathrm{r})$ line. This mainly applies to the lateral zones of the shell, where small displacement values are obtained. In these zones, transformations of vertical and horizontal components into the radial system are associated with the change in the radius of curvature $R_{\mathrm{n}}$. Unlike with the object in Ostróda, the presented example has many computational difficulties.

The lack of symmetry of the shell's deformation is very important. It causes the necessity to create an influence function for the entire arc (and not only for half the arc, as in Fig. 8). Moreover, symmetrical soil pressure on the left and right of the shell cannot be assumed, as can be seen in Figures 7 and 10. Therefore, simplifications of the model of the object in Ostróda cannot be used. With regards to these difficulties, Figure 15 presents the diagrams of pressure that was calculated from equation (5) and obtained using strain gauges. However, despite
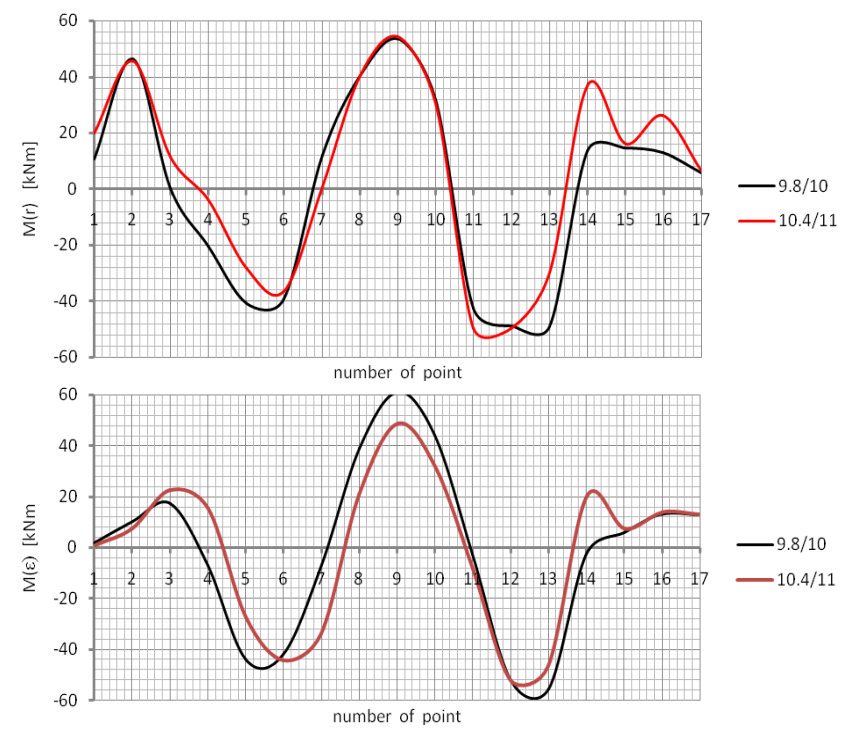

Figure 14: Comparison of the bending moment diagrams.

the asymmetrical deformation of the shell, the bending moment diagrams given in Figure 14 and the pressure diagrams given in Figure 15 are similar to the symmetrical system.

\section{Summary}

The general basic advantage of the presented algorithm of the analysis of internal forces in the corrugated metal sheet in a soil-shell object is the use of division of the structure into subsystems. This enables the circumferential band of the shell, which is separated from the object, to be analysed, and also leads to a very large reduction of the structure's model. The use of the results of strain gauge measurements in a 3D object, in combination with the influence functions of internal forces from the 2D model, gives the opportunity to assess the contact forces between subsystems. The proposed model does not take into account the displacement compatibility, i.e. slipping in the contact layer between these subsystems is permitted. This is a very important advantage of the algorithm, which reflects the principle of operation of these structures.

Good mapping of contact forces, which is shown using the examples, occurs when bending moments with a small proportion of axial forces are dominant. Therefore, the algorithm presented in the paper is adapted to monitor the construction phase, i.e. the period in which the greatest internal forces and deformations occur in the shell. The possibility of using classical geodesy devices during the construction of embankments, 


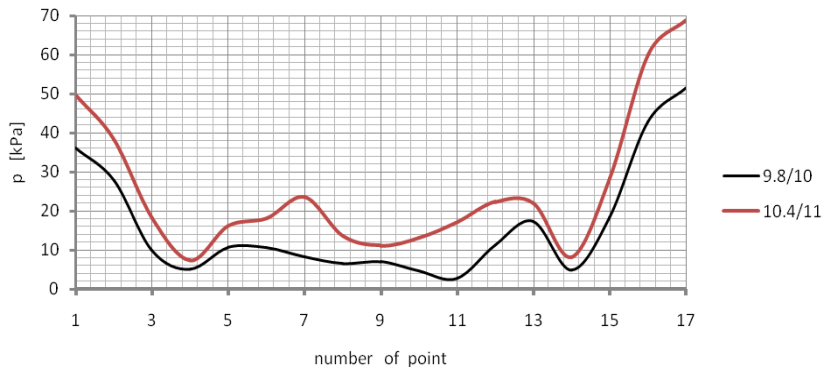

Figure 15: Diagrams of the pressures acting on the shell in the initial phase of construction of the overburden layer.

instead of specialist apparatus and the measurement base of strain gauges, is of significant importance. In the iterative algorithm proposed in the paper, it is possible to limit the number of measuring points without reducing the mesh of contact points. However, the algorithm is sensitive to measurement errors. Therefore, when there are measurement inaccuracies, correct results cannot be obtained.

The diagrams of internal forces and displacements, as well as the contact interactions that are presented in the paper, are characteristic for shells immersed in a soil medium. The pressure diagrams show the formation of a vault in the key area, which is called "the vault effect" in literature. In the support zone and the area of changes in the radius of curvature, the form of pressure is complex, and this should be considered as a local effect. Therefore, pressure depends on the shape of the shell and susceptibility of the used corrugated metal sheet. The results given in the paper can be used to model the contact layer in soil-shell structures using FEM software [20,31].

\section{References}

[1] Abdel-Sayed G., Bakht B. and Jaeger L.G.: Soil-steel bridges: Design and construction. New York McGraw-Hill Bompanies 1994.

[2] Abdel-Sayed G. and Salib S.R:. (2002) Minimum depth of soil Cover above soil-steel bridge. Journal of Geotechnical and Geoenvironmental Engineering. 128 (8) 672-681.

[3] Ahmed M.R., Tran V.D.H., Meguid M.A. : On the role of geogrid reinforcement in reducing earth pressure on buried pipes: experimental and numerical investigations, Soils and Foundations, 55 (3) (2015) 588-599.

[4] Asp 0., Laaksonen A.: Instrumentation and FE-analysis of a large span culvert built under railway. Structural Engineering International, vol. 26, no 4/2016 pp. 357-364.

[5] Bathust R.J. and Knight M.A. (1998) Analysis of geocell reinforced-soil covers over large span conduits. Computersand Geotechnics 22 (3-4) 205-2019.
[6] Beben D. and Wrzeciono M.: (2017) Numerical analysis of soil-steel composit (SSC) culvert under static loads. Steel and Composite Structures 23 (6) 715-726.

[7] Bęben D.: Experimental study on the dynamic impacts of service train loads on corrugated steel plate culvert. Journal of Bridge Engineering ASCE, 18(4), (2014), 339-346.

[8] Giges Y. and Abdel-Sayed G.: (1995) Tree-dimensional analysis of soil-steel bridges. Canadian Journal of Civil Engineering 22 (6) 1156-1163.

[9] Kunecki B.: (2014) Field test and Tree-dimensional numerical analysis of soil-steel tunnel during backfilling. Journal of the Transportation Research Board. Solid Mechanic, 2462.

[10] Łydżba D., Różański A., Sobótka M., Stefaniuk D., Chudy G., Wróblewski T.: Mechanical behaviour of soil-steel structure subjected to live load and different water conditions. Archives of Institute of Civil Engineering. (2017) 23, 163-174.

[11] Machelski C.: Soil-steel structure shell displacements functions based on tensometric measurements. Studia Geotechnica et Mechanica, No 22018 ).

[12] Machelski C.: Effects of surrounding earth on shell during construction of flexible bridge structure. Studia Geotechnica et Mechanica, No 2 2019)

[13] Machelski C.: Estimation the interaction effects of backfill on the shell in the soil-steel structure based on deformation of the shell. Przegląd Komunikacyjny 11/2016

[14] Machelski C., Kinematic method for the determination of influence function of internal forces in the steel shell of soilsteel Bridges. Studia Geotechnica et Mechanica, No 32010.

[15] Machelski C.: (2021) Characteristic features of hybrid bridge structure models. Civil and Environmental Engineering Raports, 31 (1) $44-53$

[16] Machelski C., Janusz L.: Application of Results of Test in Developing 2D Model for Soil-Steel Railway Bridges. Journal of the Transportation Research Board. Solid Mechanic, 1 (2017), 70-75.

[17] Machelski C., Mońka M., Tomala P.: Monitoring of soil-steel structures during construction. Journal of Current Construction Issues 2/2019 159-168.

[18] Maleska T. and Beben D. (2019) Numerical analysis of soil-steel bridge during backfilling using various shell models. Journal Engineering Structures 196 (1) 1-12.

[19] McVay M., Papadopoulos P. : Long term behavior of buried large-span culverts, Journal of Geotechnical Engineering, 112 (4) (1986) 424-442,

[20] Mellat, A. Anderson, L. Pettersson, Karuomi R.: Dynamic analysis of a short span soil-steel composite bridge for railways traffic using field measurements and numerical modelling. Engineering Structures, 69, 2014, 49-61.

[21] Milewski S. : Meshless Finite Diference Method with Higher Order Approximatio-Applications in Mechanics. Arch. Comput. Methods Eng. (2012) $19: 1-49$

[22] Orkisz J. : Finite Difference Method (part III). Handbook of Computetional Solid Mechanics 336-431. Springer-Verlag, 1998.

[23] Pettersson L. Flaner E.B, and Sundquist H.: (2015) Design of soil-steel composite bridges. Structural Engineering International 25 (2) 159-192.

[24] Simpson B., Hoult N.A and Moore I.D (2015) Distributed sensing of circumferendial strain using fiber optics during 
full-scale buried pipe experiments. Journal of Pipeline Systems Engineering and Practice 6 (4) 04015002-1-04015002-10.

[25] Sobótka M. Numerical simulation of hysteretic live load effect in soil-steel bridge. Studia Geotechnika et Mechanica. (2014) 36.1. 103-109.

[26] Sobótka, M. (2020). Shape optimization of flexible soilsteel culverts taking non-stationary loads into account. Structures, 23, 612-620.

[27] Sobótka, M., \& Łydżba, D. (2019). Live load effect in soil-steel flexible culvert: role of apparent cohesion of backfill. European Journal of Environmental and Civil Engineering, 1-15.

[28] Sobótka, M., \& Machelski, C. (2016). Hysteretic live load effect in soil-steel structure. Engineering Transactions, 64(4), 493499.

[29] Taleb B and Moor I.D (1999) Metal culvert response to earth loading: performance of two-dimensional analysis. Transportation Research Record (1656) 25-36.

[30] Tomala P., Nowak M., Samolewski W., Szyszka M.: SoilSteel Composite Structure Monitoring During Bacfilling and Uncovering - Observations and Remarks. Conf. Transportation Research Board of Nationals Academies, Washington D.C., 12-15 January 2019.

[31] Wadi A., Pettersson L., Karoumi R. : Flexible culverts in sloping terrain. Numerical simulation of avalanch load effects. Enginering Structure $2015 ; 101 ; 111-24$

[32] Vaslestad J. : Soil structure interaction of buried culverts. Doktoral Ingenioravhandling 1990 :7. Instytut for Geoteknikk Trondheim.

[33] Yeau K.Y, Halil S. (2014) Simulation of behavior of in-service metal culverts. Journal of Pipeline Systems Engineering and Practice 5 (2) 04013016.

[34] Yu W.S., Li Z.L., Xie X.R., Guo L.Y. : Experimental study on earth pressure of corrugated steel culvert under high fill embankment, Applied Mechanics and Materials, 405-408 (2013) 1815-1819. 